\title{
About venous malformations of the facial bones
}

\author{
Margherita Dessy $^{1} \cdot$ Federica Giovanditto $^{1} \cdot$ Marco Cucurullo $^{1} \cdot$ Ambra Dionisio $^{1} \cdot$ Carlotta Liberale $^{1}$. \\ Giacomo Colletti ${ }^{1}$ (iD
}

Received: 18 April 2018 / Accepted: 4 June 2018 / Published online: 14 June 2018

(C) Springer-Verlag GmbH Germany, part of Springer Nature 2018

\section{Dear Sir,}

We read with genuine interest the paper from Fàbiàn and coworkers (https://doi.org/10.1007/s10006-018-0691-0). The authors have made an admirable (and effective) effort in reviewing the current literature on vascular malformations of the facial bones. We believe that they have made the point in underlining how, despite an effortless work of ISSVA, there is still confusion, misdiagnosis, and thus improper treatment of many cases. In particular, venous malformations (VMs) continue to be oftentimes named "hemangiomas" or "cavernous hemangiomas." We totally agree on this as we have previously published [1]. Fàbiàn et al. reveal how frequently this mistake is still perpetrated, and this is the first reason why the authors should be congratulated. Then they meticulously describe the clinical history of the case with emphasis on the role of previous improper approaches to the patient's disease that likely caused an accelerated increase of the malformation volume. A cause-relation effect was never reported so clearly before.

On the other hand, we believe that there are some debatable statements on this remarkable paper.

First, they describe preoperative superselective embolization as useful and advisable in a multidisciplinary management of bony VMs. This is not our experience. Transarterial embolization will never succeed in reducing blood flow to a VM of the facial bones because they are nourished by a randomly distributed pattern of very small arterial feeders that are not identifiable and amenable of endovascular closure. We have previously discussed this $[2,3]$. Even strangling the external carotid artery is pointless for the very same reason. So, whenever a physician is able to preoperatively diagnose a bony VM (and this is easy in an expert setting), he or she

Giacomo Colletti

giacomo.colletti@gmail.com

1 Department of Maxillo Facial Surgery, University of Milan, via A. diRudini, 8, 20100 Milan, Italy should never have the patient undergo angiography and embolization.

Then the authors, at the end of the paper, suggest that an early diagnosis and treatment is desirable by means of surgery or sclerotization. In our experience with 12 cases, we disagree on this because the mainstay of whichever sclerosing session is to reach (and, more importantly, stay within) the malformed vessels. This is, from a practical point of view, very easy to do with VMs of the soft tissues, with US or phlebographic guidance, but is undoable in VMs of the bone because they are made of very small chambers with frail vessels that are either unreachable or broken causing leakage of the sclerosant with a predictable increase in complications [4] and a very low-tonone effectiveness.

A multidisciplinary discussion of the case involving an expert in endovascular management of vascular malformations would likely agree with these considerations [5].

\section{References}

1. Colletti G, Deganello A (2016) Cavernous hemangioma: a term to be canceled. Eur Arch Otorhinolaryngol 274(4):2069-2070. https://doi. org/10.1007/s00405-016-4324-7

2. Colletti G, Frigerio A, Giovanditto F, Biglioli F, Chiapasco M, Grimmer JF (2014) Surgical treatment of vascular malformations of the facial bones. J Oral Maxillofac Surg 72(7):1326.e1-1326.18. https://doi.org/10.1016/j.joms.2014.02.012

3. Colletti G, Ierardi AM (2017) Understanding venous malformations of the head and neck: a comprehensive insight. Med Oncol 34(3):42. https://doi.org/10.1007/s12032-017-0896-3

4. Colletti G, Deganello A, Bardazzi A, Mattassi R, Dalmonte P, Gazzabin L, Stillo F (2017) Complications after treatment of head and neck venous malformations with sodium tetradecyl sulfate foam. J Craniofac Surg 28(4):e388-e392. https://doi.org/10.1097/SCS. 0000000000003723

5. Colletti G, Valassina D, Bertossi D, Melchiorre F, Vercellio G, Brusati R (2014) Contemporary management of vascular malformations. J Oral Maxillofac Surg 72(3):510-528. https://doi. org/10.1016/j.joms.2013.08.008 